\title{
Cultural heritage and earthquakes: bridging the gap between geophysics, archaeoseismology and engineering
}

\author{
Laura Pecchioli • Francesco Panzera • Valerio Poggi
}

Published online: 18 June 2020

C) The Author(s) 2020, corrected publication 2021

\section{Introduction}

Historical sites, monuments and constructions of architectural importance are part of the world's cultural heritage $(\mathrm{CH})$ and are of unquestionable value for our society. UNESCO recommendations foresee preserving cultural and natural sites of "outstanding universal value" as heritage of humanity for present and future generations. As with every element in the built environment, cultural heritage sites are particularly vulnerable to extreme natural events such as earthquakes and their associated secondary effects (e.g. landslides, ground failures, tsunamis). Recent earthquakes in Italy, Turkey and Greece (e.g. Umbria-Marche 1997, Izmit and Duzce 1999, Central Italy 2016, Kos 2017) caused the loss of invaluable historical assets and have emphasized the increased need for targeted mitigation actions to preserve the vast cultural and historic heritage from natural

\section{Pecchioli}

Winckelmann-Institute/Classical Archaeology/OFP, Humboldt University, Berlin, Germany

\section{Pecchioli $(\bowtie)$}

Department Building Archaeology and Built Heritage Conservation, Technical University of Berlin, Berlin, Germany e-mail: laura.pecchioli@hu-berlin.de

F. Panzera

Swiss Seismological Service, ETH, Zürich, Switzerland

V. Poggi

National Institute of Oceanography and Applied Geophysics, OGS, Udine, Italy disasters. It is well known, however, that targeted measures are not sufficient, unless they are coordinated into common disaster risk reduction (DRR) policies, capable of harmonizing the contributions from a spectrum of professional profiles.

Especially in the last 10 years and in the context of the World Heritage Convention, different charters and guidelines have been developed trying to foster a holistic, multidisciplinary approach through the involvement of different experts. An important milestone, relative to natural disasters, was reached in 2010 with the Resource Manual on the Managing Disaster Risks for World Heritage: the UNESCO, ICCROM (International Centre for the Study of the Preservation and Restoration of Cultural Property), ICOMOS (International Council on Monuments and Sites) and IUCN (International Union for Conservation of Nature) published for the first time a guidance for site managers requiring disaster risks management plans as part of an overall site management system (UNESCO, 2010). To help the people involved to undertake integrated disaster risk assessment of cultural heritage, the guide highlights the need of interdisciplinary training courses. The ICOMOS itself has defined charters and guidelines about recording and documentation, and provides training and education activities focusing on the role of experts involved as part of multidisciplinary teams. Among various other important recent contributions, a final technical implementation report of the P.A.T.C.H. -Prevention Analysis and Tools for Cultural Heritage (2012) was developed, with the goal of creating a detailed scenario of the earthquakes' impact on cultural heritage in pilot areas and 
analysing the existing cultural heritage emergency management and prevention measures through a series of surveys from each contributing partner. Also in this case, innovative intervention practices were elaborated, in order to make operators with different specialized competencies and skills able to handle the situation and to cooperate as a team.

These are just a few important documents and legislative framework for cultural heritage, but it is nowadays clear that the preservation of the existing cultural and built heritage requires the use of state-of-art science, knowledge and information, and involves the interaction between scientists of different, although complementary, research fields. Unfortunately, sometimes the lack of interdisciplinary approach leads to real consequences such as in the case of post-disaster recovery for Calabria (1783), Irpinia (1980) and Belice (1986) earthquakes, where recovery interventions were organized using inappropriate materials, styles and reconstruction techniques. Because of this, several villages were abandoned and people eradicated from their houses, as a clear evidence that reconstruction projects cannot simply ignore the history, memory and identity of places. On the contrary, a noticeable wellestablished example of interdisciplinary approach is instead the Friuli 1976 earthquake, where the houses and monuments of many villages (e.g. Venzone) were rebuilt in the same places using the actual ruins and following the original layouts.

Another noteworthy example of interdisciplinary collaboration is in the frame of seismic hazard assessment. In particular, instrumentally recorded earthquake catalogues are often limited to the last 40-50 years, not enough to properly evaluate the seismic hazard associated to the largest and thus more threatening events which usually have long recurrence time intervals. To overcome this limitation, earthquake catalogues are then extended hundreds to thousands years by including events reconstructed from indirect historical and palaeoseismological evidences. Nonetheless, a correct evaluation of these earthquakes is only possible thanks to the close collaboration of seismologists with historians (e.g. for reconstruction of past earthquake chronicles), archaeologists (e.g. for evidences of past damage on archaeological sites), geologists (geochronological analysis of seismogenic faults; analysis of seismites in sedimentary records) and geophysicists (geodetic deformation and palaeo stress-field definition). Likewise, the reconstruction of the damaging process in ancient structures would not be possible without the proficuous interaction of archaeologists with structural engineers.

Multidisciplinary research, however, is not always straightforward. It primarily requires the definition of a common language, which is essential to allow scientists sharing opinions and experiences and, at the same time, setting up common objectives. Unfortunately, until the recent past, legacy academic attitudes and profound diversity in background have often led to difficult interactions between the different research fields.

This special issue is thus focused on the multidisciplinary approach to cultural heritage preservation, with special care to the impact of earthquakes and their associated effects. For that, we have collected a number of representative studies involving the different research fields, each addressing the problem through a specialized methodological perspective. The final goal is to set up a common ground for interaction, highlighting the need for scientific collaboration and coordinated intervention. Below, we briefly summarize the main contributions to this special issue, which have been rationally sorted to highlight the diversity in the backgrounds of the different authors and in their methodological approaches, but at the same time to emphasize similar aspects of the addressed problematics and common objectives.

In the first article, an exhaustive report on archaeoseismology of South Asia, as well as the 2015 Gorkha earthquakes, is illustrated by Davis et al. (2020). Multidisciplinary post-disaster investigations are linked to architectural and engineering studies from 2015 to 2018. It offers an inventory of archaeological evidence of earthquakes and seismic adaptations of historic buildings within Kathmandu Valley, Nepal. The contribution brings to light many primary evidences that help reconstruct damage, adaptations, resilience and reactions of past societies towards earthquakes.

For the purpose of better understanding the impact of local geological conditions on the damage level experienced during past historical earthquakes on the temple structures in the Archaeological Park of Selinunte (Sicily, Italy), Schwellenbach et al. (2020) provide in their study an exhaustive discussion on the combined use of active and passive seismic techniques to evaluate the main structural characteristics of the subsoil, with application to a selected number of target sites.

Similarly, Salonikios et al. (2020) analyse the seismic response and the associated damage distribution at two Thessaloniki monuments with different structural 
systems through ambient vibration measurements and modelling. The main results are the calibration of reliable finite element models useful to evaluate the structures' response to potential earthquake ground motions that might strike the studied areas in future.

Grigoratos et al. (2020) discuss the reappraisal of the available historical sources for the development of a new parametric earthquake catalogue for the Dead Sea Transform Fault Zone (STFZ) in the period 31 BC to 1900. The authors have reviewed the existing parametric information from various sources and, whenever possible, compared with any evidence from geological and archaeological field investigation studies.

Marra et al. (2020) present a multidisciplinary study, involving geologists and seismologists, aimed at investigating the origin of seismic damages affecting several ancient buildings in the Roman port city of Ostia. The main outcome is that the observed damage may be the consequence of local events and not only related to the strong Apennines' seismogenic sources.

Stiros (2020) investigated the peculiar seismic performance of the Monumental Articulated ancient Greek and Roman (MAGR) columns and temples, by comparing the response of structures being damaged by known and unknown causes, with particular regard to the effect of dynamic soil response variability. From this analysis, the author concluded that MAGR structures are not intrinsically vulnerable to earthquakes, but their seismic fragility strongly depends on the level of structural deficiency progressively accumulated over time.

Rodríguez-Pascua et al. (2020) focus their contribution on the description and analysis of earthquake archaeological effects (EAEs) affecting archaeological remains to identify ancient earthquakes at Machu Picchu, in an area lacking instrumental and historical seismicity. This study is an important step in filling the gap in knowledge regarding archaeoseismology in South America. It uses a novel way to filter out the effect of the slope from the measured effects of seismic damage.

The manuscript of Iannucci et al. (2020) describes passive seismic measurement results of a complex landslide process involving the area of the Ghajn Hadid Tower, on the NE coast of the Malta island. The analysis of ambient vibrations using a seismic array configuration allowed retrieving the shear wave velocity profile by using a joint inversion approach, considering HVSR and Rayleigh wave dispersion curves. Moreover, significant strongly polarized HVSR peaks were observed.

As a concluding remark, we hope that the natural diversity of the selected topics in this special issue will be helpful for the reader to further promote the natural cooperation and coordination between the diverse research fields, contributing to the preservation of the world's invaluable cultural heritage from earthquakes and their related effects.

Acknowledgements The Guest Editors are grateful to all the authors for their close cooperation whilst preparing their contributions. They also gladly acknowledge all referees from a number of research institutions worldwide. Their careful reading and constructive suggestions contributed to the standard of the final versions of papers presented in this special issue. Special thanks go to the Editor-in-Chief Prof. Mariano Garcia-Fernandez and the Journal staff for their professional assistance and technical support during the entire publishing process that has led to the realization of this thematic issue.

Funding Open Access funding enabled and organized by Projekt DEAL.

Open Access This article is licensed under a Creative Commons Attribution 4.0 International License, which permits use, sharing, adaptation, distribution and reproduction in any medium or format, as long as you give appropriate credit to the original author(s) and the source, provide a link to the Creative Commons licence, and indicate if changes were made. The images or other third party material in this article are included in the article's Creative Commons licence, unless indicated otherwise in a credit line to the material. If material is not included in the article's Creative Commons licence and your intended use is not permitted by statutory regulation or exceeds the permitted use, you will need to obtain permission directly from the copyright holder. To view a copy of this licence, visit http://creativecommons.org/licenses/by/4.0/.

\section{References}

Davis C., Coningham R., Acharya K. P., Kunwar R. B., Forlin P., Weise K., Maskey P. N., Joshi A., Simpson I., Toll D., Wilkinson S., Hughes P., Sarhosis V., Kumar A. and Schmidt A. (2020). Identifying archaeological evidence of past earthquakes in a contemporary disaster scenario: casestudies of damage, resilience and risk reduction from the 2015 Gorkha Earthquake and past seismic events within the Kathmandu Valley UNESCO World Heritage Property (Nepal). Journal of Seismology (This issue)

Grigoratos I., Poggi V., Danciu L and Rojo G. (2020). An updated parametric catalog of historical earthquakes around the Dead Sea Transform Fault Zone. Journal of Seismology (This issue)

Iannucci R., Martino S., Paciello A., D’Amico S., Galea P. (2020). Investigation of cliff instability at Ghajn Hadid Tower 
(Selmun Promontory, Malta) by integrated passive seismic techniques. Journal of Seismology (This issue)

Marra F., Milana G., Pecchioli L., Roselli P., Cangi G., Famiani D., Mercuri A. and Carlucci G. (2020). Historical faulting as the possible cause of earthquake damages in the ancient Roman port city of Ostia. Journal of Seismology, issue ..., pp ...

P.A.T.C.H. - Prevention Analysis and Tools for Cultural Heritage (2012). Final technical implementation report, guidelines, protocols and procedures for the rescue of cultural heritage items during seismic events, European Commission Directorate General for Humanitarian Aid and Civil Protection, Edited by Fabrizio Boldrini, E. Consuelo Caputo, Marco Conti, Christie Sarri

Rodríguez-Pascua M.A., Benavente Escobar C., Rosell Guevara L, Grützner C., Audin L., Walker R., García B. and Aguirre E. (2020). Did earthquakes strike Machupicchu? Journal of Seismology (This issue)

Salonikios T., Theodoulidis N. and Zacharopoulou G. (2020). Seismic response evaluation of monuments based on ambient vibrations: the case studies of a Byzantine basilica and an Ottoman bath in Thessaloniki (Greece). Journal of Seismology (This issue)

Schwellenbach I., Hinzen K-G, Petersen G. M. and Bottari C. (2020). Combined use of refraction seismic, MASW and ambient noise array measurements to determine the near surface velocity structure in the Archaeological Park of Selinunte, SW Sicily. Journal of Seismology (This issue)

Stiros S. C. (2020). Monumental articulated ancient Greek and Roman columns and temples and earthquakes: archaeological, historical and engineering approaches. Journal of Seismology (This issue)

UNESCO (2010), Managing disaster risks for world heritage, UNESCO World Heritage Center, Paris. https://whc.unesco. org/en/managing-disaster-risks/, last accessed 29 May, 2020

Publisher's note Springer Nature remains neutral with regard to jurisdictional claims in published maps and institutional affiliations. 